It was a similar case of mixed and modest blessings for the research granting councils. CIHR, the Natural Sciences and Engineering Research Council (NSERC) and the Social Sciences and Humanities Research Council (SSHRC) received a collective $\$ 32$ million - \$16 million, \$13 million and \$3 million, respectively — increase in their base operating budgets. But that doesn't offset the collective \$43-million hit they took for fiscal 2010/11 or the collective \$87.1-million hit they'll take for fiscal 2011/12 as a result of measures announced in the 2009 budget. The net effect is a reduction in the actual amounts available for research operating grants, albeit not as severe as originally scheduled.

'It doesn't even begin to keep up with inflation, let alone offset last year's cuts," says Jim Turk, executivedirector of the Canadian Association of University Teachers.

Nor was there any sign of money for CIHR President Dr. Alain Beaudet's proposal to lay the groundwork for a national initiative on Alzheimer disease and related dementias (CMAJ 2010. DOI:10.1503/cmaj.109-3064 and CMAJ
2009. DOI:10.1503/cmaj.091124).

Finance officials say the government no longer disaggregates granting council operating grant allocations in the overall council budgets, which include funds for a host of training and scholarship programs as well as other special allocations, such as money for targeted industry partnership programs or the Canada Research Chairs program. The upshot, the officials said, is that CIHR's global budget will rise to $\$ 986.7$ million from $\$ 980.3$ million, while NSERC's will decline to $\$ 1.022$ billion from $\$ 1.039$ billion and SSHRC's will drop to $\$ 680$ million from $\$ 685.1$ million. The SSHRC budget includes government funds for the Indirect Costs of Research Program, which will rise $\$ 8$ million to $\$ 333$ million, to help universities allay administrative and overhead costs associated with conducting research.

"It's all good news," said one veteran Finance official.

And, as federal governments for decades have been wont to do in the face of calls to invest heavily in research, Prime Minister Stephen Harper's Conservative government announced it will launch yet another review of federal science spending to again determine if taxpayers are getting the best bang for their buck.

The rationale for launching the exercise is to align outlays largely along commercialization objectives, the budget states. "To ensure that federal funding is yielding maximum benefits for Canadians, the Government, in close consultation with business leaders from all sectors and our provincial partners, will conduct a comprehensive review of all federal support for R\&D to improve its contribution to innovation and to economic opportunities for business. This review will inform future decisions regarding federal support for R\&D. The Government is currently developing the terms of reference for the review."

Turk says the clear intent is to find more ways of linking university research to industry. "They're throwing more and more public money into programs at the granting councils and otherwise to divert people into partnerships with industry." — Wayne Kondro, CMAJ

DOI:10.1503/cmaj.109-3201

\title{
Global shift toward increased biovigilance
}

Previously published at www.cmaj.ca

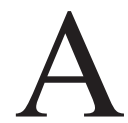
global movement toward increased biovigilance is resulting in the rapid rollout of Canadian, American and European initiatives aimed at developing national surveillance systems for cells, tissues and organs.

The Public Health Agency of Canada is leading the development of a reporting and surveillance system that will track and analyze adverse events in the transplantation of products of human origin. The system will collect data on moderate and severe adverse events eventually expanding to include serious errors and near misses - to monitor trends in known and emerging risks and reduce the transmission of infectious diseases due to transplantation.

Nova Scotia, Quebec and Alberta were recently chosen as pilot provinces

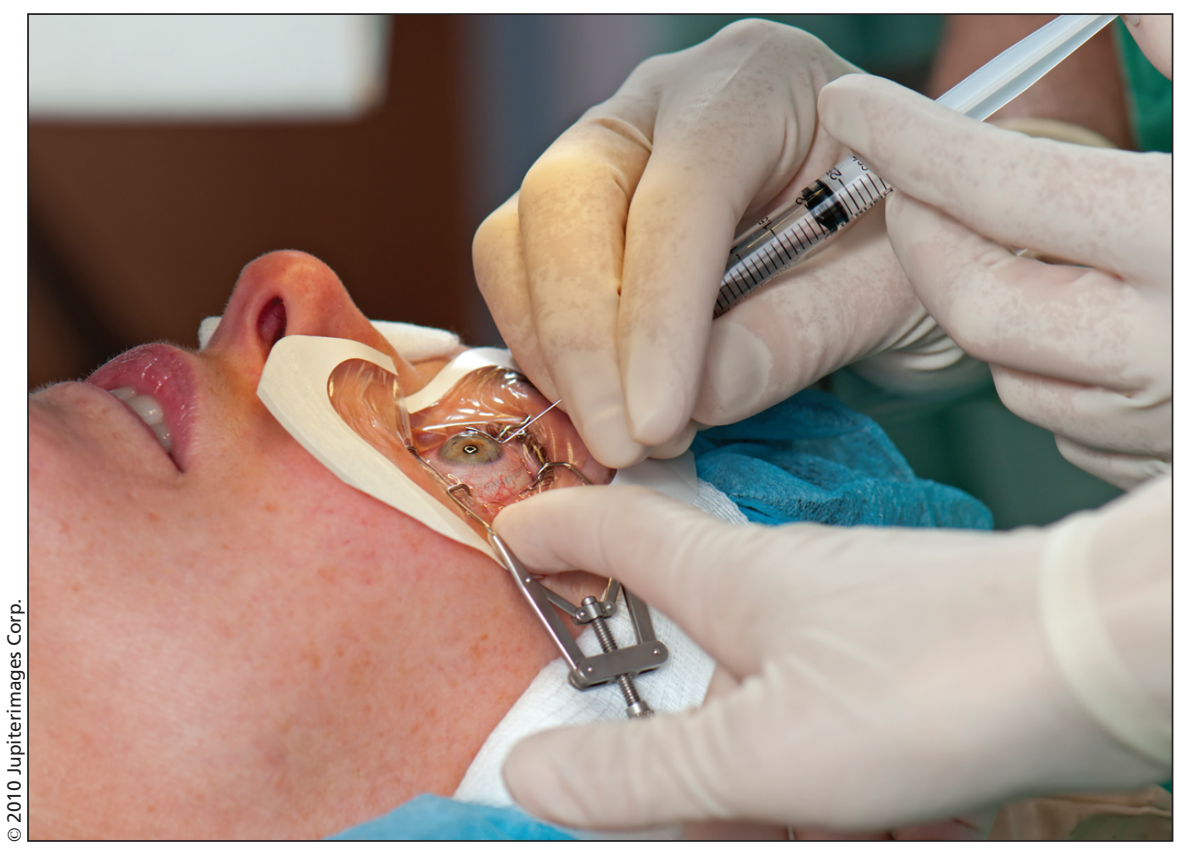

Cornea transplants are among the most common forms of tissue transplantation. 
for the first phase of the initiative, which will primarily focus on tissues; the province's blood coordinating program was selected to implement the system, after being singled out for its past success with the Transfusion Transmitted Injuries Surveillance System. (CMAJ 2010. DOI:10.1503/cmaj.109-3195).

The shift toward increased biovigilance - the systematic surveillance and analysis of untoward and unexpected events in blood transfusion and the transplantation of cells, tissues and organs has only emerged in recent years, says Dr. Matthew Kuehnert, director of the Office of Blood, Organ and Other Tissue Safety for the United States Center for Disease Control (CDC).

"In hemovigilance, the United States has been behind Canada and Europe for quite some time now, but we're rapidly catching up," Kuehnert says. "However, when it comes to biovigilance, we're all starting on the same level playing field, because until recently the emphasis for organs and tissues has always been on availability first and foremost."

The CDC, in partnership with other public and private agencies in the US, launched a transfusion recipient surveillance system in February as part of phase one of a new national biovigilance network. It's the first in a series of integrated surveillance systems that the network is developing to reduce adverse reactions and incidents in blood transfusions and other biological therapies.

The first phase of the network's implementation will focus on hemovigilance, with a second surveillance system scheduled to launch later this year to track adverse reactions associated with the donation process at blood collection sites.

Transfusion services will be able to voluntarily and confidentially report data on adverse events to the CDC's preexisting National Healthcare Surveillance Network for analysis, and will have the chance to compare their results with those of other facilities in the aggregate.

The second phase of the network's implementation will see the development of a surveillance system for cells, organs and tissues in addition to the current hemovigilance module. But Kuehn- ert says there's no definite timeframe for when those systems might launch.

Until recently, the US was one of the only developed countries in the world without a national hemovigilance program, says Dr. Barbee Whitaker, director of data and special programs for AABB, formerly the American Association of Blood Banks, which along with the CDC is spearheading the development of the biovigilance network.

"It's not that we haven't been categorizing transfusion reactions, we just didn't have a centralized reporting system for everyone to use, largely because we are hindered by our medical system in ways other countries with national healthcare systems are not," she explains. "The sheer size of our system alone means that if we can get even $10 \%$ of the transfusion services in the country to voluntarily join on, we'll have the largest hemovigilance system in the world."

As of mid-February, roughly 60 of the approximate 4000 transfusion sites in the US had volunteered to enrol with the new surveillance system, says Whitaker.

Former AABB president Dr. Michael Strong says the notion of creating vigilance and surveillance systems for various biological therapies first took hold in the US in 2005. "Around that time, there were a number of well-publicized cases of infectious disease transmission from organs and tissues and that really got the ball rolling. I remember one dentist had set up a tissue recovery program in a funeral home unbeknownst to families, and was falsifying documents and recovering something in the excess of 25000 tissue grafts, many of which were exported outside the States and couldn't be traced."

Scandal, he suggests, has been a good motivating factor for change.

"Even going back to the hemovigilance programs pioneered in the early nineties, France was well ahead of its time partly because of a major scandal surrounding HIV-tainted blood," Strong explains. "As a direct result, they funded a mandatory hemovigilance program and put transfusion safety officers in all their hospitals."

Outside North America, changes in regulations have also led to consider-
Looking for sustained power?

\section{Look at HUMIRA for Crohn's disease}

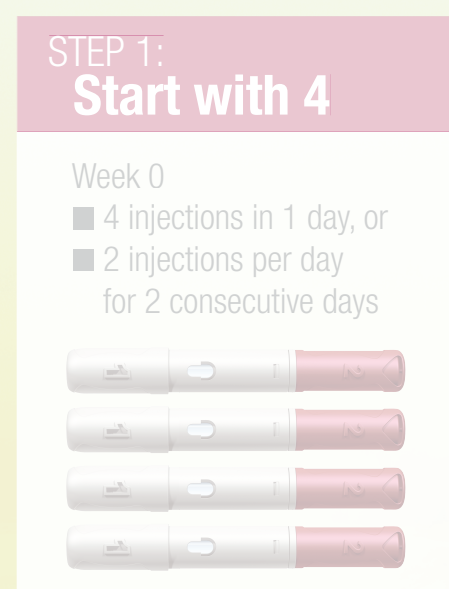

\section{STEP 2: Move to 2}

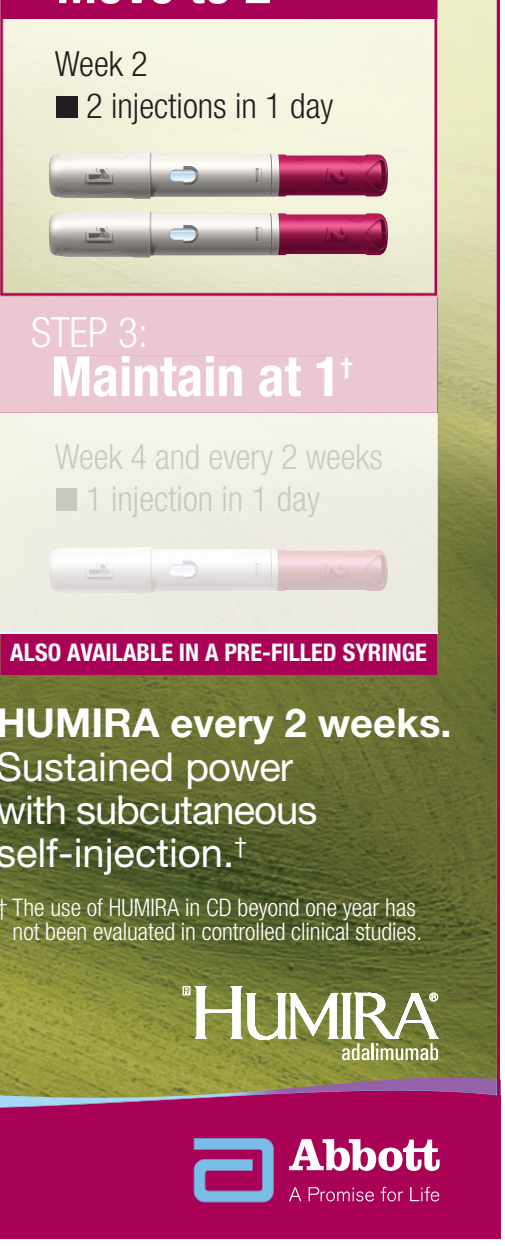


able progress in the field of biovigilance, says Dr. Luc Noël, in charge of transplantation at the World Health Organization (WHO).

"In the last decade, the European Commission established directives requiring the vigilance and surveillance of cell and tissue transplantation and blood transfusions, and now there is a new directive for surveillance of organ transplantation practices that we hope will be put through in the coming months," he says. "These directives have resulted in projects like the Euro- pean Union Standards and Training for the Inspection of Tissue Establishments Project, which ran for three years and focused on inspection training and vigilance for tissue banks but also created tools that can now be used internationally for biovigilance and surveillance."

The project developed tools and assessment grids for member states of the European Union that can help identify how an adverse event should be reported and calculate the appropriate level of national and international reaction.

Those tools have since been stream- lined by the WHO for global application and were debuted at the Third Global Consultation on Regulatory Requirements for Human Tissues and Cells for Transplantation in Geneva, Switzerland in February.

WHO has also started development on a Global Knowledge Base on Transplantation, which lay people and regulatory authorities will be able to use to access information on biovigilance and surveillance. - Lauren Vogel, Ottawa, Ont.

DOI:10.1503/cmaj.109-3196

\section{Where "stigma leaves the room"}

Previously published at www.cmaj.ca

$\mathrm{W}$ hen Lt. Col. Stéphane Grenier returned to Canada in 1995 from a 10-month peacekeeping mission in Rwanda, he was as an injured man. He just didn't know it.

He had been part of the United Nations forces, under Lt. Gen. Roméo D'Allaire, who were caught in the middle of the militia-led massacre of 800000 Tutsis and moderate Hutus. For four years after his return, Grenier suffered from cold sweats, flashbacks, emotional outbursts and sleepless nights. He once sat in his car for 45 minutes outside a base clinic, trying to figure out how he was going to describe what was going on in his head.

Looking back, Grenier realizes he was oblivious to anything related to mental health problems. Now, as special adviser on operational stress injuries for the Canadian Forces, he is leading an effort to educate Canadian soldiers about mental health, so they will be better equipped to recognize and seek help for invisible wounds, like the post-traumatic stress disorder he came home with 15 years ago.

"We sometimes see mental health as less important than it should be, because we don't have the right language to describe it," Grenier says.

Simply being made more aware of mental health issues is not enough, says Grenier. A pamphlet won't cut it. So he created an educational campaign to reach military personnel of all ages, ranks and level of development. The

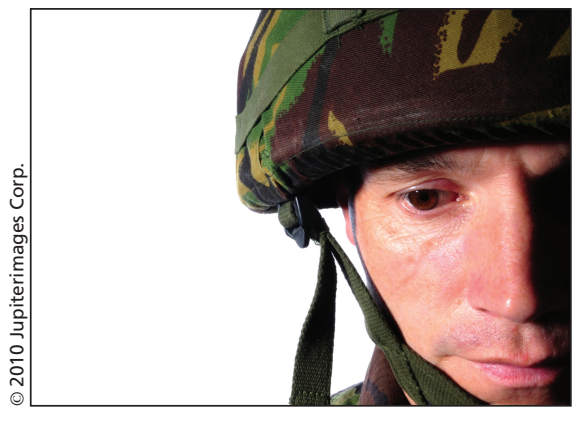

Soldiers are sometimes unaware that they return from combat with mental wounds, but the Canadian Forces is teaching them to recognize the signs.

goals are to educate them about mental injuries, to reduce stigma surrounding mental health problems and to change attitudes about seeking help.

One section is dedicated to broadening soldiers' understanding of what operational stress injuries are. For example, soldiers are taught that in addition to seeing a traumatic event, fatigue can lead to a mental health problem. The wear and tear of long days in the field adds up, says Grenier. "There's a cumulative effect on the body and the mind."

Other triggers include grief suffered because of the deaths of fellow soldiers and what Grenier refers to as "moral injuries," when the experiences of war affect core values, causing people to question beliefs they may have held their entire lives.

Another component of the education campaign is the teaching of a mental health continuum model that was developed in consultation with the United States Marines Corp. The old model of mental health, says Grenier, was too black and white - you were mentally sound or mentally ill. Soldiers learn that the mental health spectrum is more complex, and that all health, mental and physical, is dynamic and can worsen or improve depending on a person's circumstances. The continuum model consists of multiple stages: healthy, adaptive coping, mild and reversible distress, functional impairment, persistent impairment and clinical illness requiring concentrated care.

"We look at behaviours in the workplace and we give examples of problem behaviours at different stages, and we tell people what to do in each of these stages," says Grenier.

The mental health education is administered using an experiential approach rather than one based on traditional clinical theories. Soldiers tend to listen better to people who share their culture, Grenier says, so instructors include mental health professionals and members of the military who have suffered problems.

The instructors don't reveal their own stories right away, though, instead waiting until they have established credibility with the class. When they do disclose what they have been through, the effect on the students is apparent, says Grenier.

"Jaws drop," he says. "And stigma leaves the room." - Roger Collier, CMAJ

DOI:10.1503/cmaj.109-3197 